\title{
A method of transcutaneously adjustable pulmonary artery banding for staged left ventricular retraining
}

\author{
Daniel J. DiBardino, MD, Kellianne Kleeman, BS, and Edward L. Bove, MD
}

\begin{abstract}
Objectives: The placement of a pulmonary artery band to retrain the left ventricle often requires reoperation for band adjustment. We describe an effective technique for the placement of a transcutaneously adjustable pulmonary artery band that allows adjustments to be made without the need for repeat sternotomy.
\end{abstract}

Methods: Using standard catheters, an adjustable band was fashioned and placed around the pulmonary artery
with the control end positioned in the subcutaneous tissue of the anterior chest wall. Tightening or loosening of
the band can be subsequently performed by exposing the control end without the need for reopening the chest.

Results: From 1995 to 2011, 11 patients underwent placement of a transcutaneously adjustable pulmonary artery band for the purpose of retraining the morphologic left ventricle for a subsequent arterial switch operation. One or more band adjustments were required in 6 patients ( 1 loosened and 5 tightened, 55\%) at a mean of 281 days (median, 98; range, 0-917) after initial band placement. All were accomplished successfully by exposing the band in the subcutaneous tissue of the anterior chest wall and performing the adjustment under Doppler echocardiographic guidance.

Conclusions: This technique affords the operating surgeon the freedom to apply the band very gradually, erring on the side of safety, and facilitates a gradual increase in ventricular afterload that can be performed as a minor procedure. (J Thorac Cardiovasc Surg 2012;144:553-6)

The application of a pulmonary artery band for the purpose of left ventricular (LV) retraining has been used for patients with d-transposition of the great arteries (d-TGA) who present at an older age for an arterial switch procedure, reversal of a previous atrial level switch in the face of a failing systemic right ventricle, and preparation of the left ventricle for a combined arterial and atrial switch operation in patients who have congenitally corrected transposition of the great arteries with low morphologic LV pressure. Although the former 2 indications are seen with less frequency, given the widespread use of the arterial switch repair for neonates with d-TGA and the diminishing population of patients from the atrial switch era, the population of patients with congenitally corrected transposition of the great arteries continues to be a challenging one. Some of these patients will develop tricuspid valve regurgitation with decreased morphologic right ventricular function, and LV retraining has been used in an effort to perform a combined arterial/ atrial repair or double switch operation. However, the placement of a pulmonary artery band for this purpose is an

\footnotetext{
From the Section of Cardiac Surgery, Division of Pediatric Cardiac Surgery, CS Mott Children's Hospital, University of Michigan Medical School, Ann Arbor, Mich. Disclosures: Authors have nothing to disclose with regard to commercial support. Received for publication April 14, 2011; accepted for publication Sept 15, 2011; available ahead of print Feb 9, 2012.

Address for reprints: Daniel J. DiBardino, MD, Section of Cardiac Surgery, Division of Pediatric Cardiac Surgery, CS Mott Children's Hospital, University of Michigan Medical School, 5144 CVC/SPC 5864, 1500 East Medical Center Drive, Ann Arbor, MI 48109-5864 (E-mail: Daniel.DiBardino@gmail.com). $0022-5223 / \$ 36.00$

Copyright (c) 2012 by The American Association for Thoracic Surgery doi:10.1016/j.jtcvs.2011.09.077
}

imprecise procedure, often requiring reoperation for band adjustment and arbitrary decisions regarding how tight a particular adjustment can be at each individual encounter.

Since 1995, one of us (E.L.B.) has relied on a straightforward, simple, and effective technique for the placement of a transcutaneously adjustable pulmonary artery band (TAPAB) that allows adjustments to be made without the need for repeat sternotomy. In the present report, the technique and outcomes of patients undergoing this procedure are described.

\section{METHODS}

After institutional review board approval, all patients undergoing pulmonary artery banding at the University of Michigan CS Mott Children's Hospital using the TAPAB were identified. The basic demographics, cardiac diagnoses, Doppler/echocardiographic and cardiac catheterization results, operative details, and subsequent disposition, including band adjustments, other operations, and procedures, and the most recent status were taken from a review of the electronic record chart. The data were collected and stored on a Microsoft Excel spreadsheet (Microsoft, Redmond, WA), and the appropriate data reported as the mean or median, as noted, with the ranges.

\section{TABAP Construction and Application}

The back end of an $8 \mathrm{~F}$ Kendall Argyle feeding tube (Tyco Health Care Group, Mansfield, Mass) is fed through the first hole at its tip and pulled through, resulting in a loop that can be placed around the pulmonary artery (Figure 1). A 14F Coloplast straight tip male urinary catheter (Coloplast, Humlebaek, Denmark) is then trimmed to an appropriate length and advanced over the back end of the feeding tube to function as a tourniquet. The distal end of the tourniquet is fixed with sutures to the outer portion of the feeding tube, allowing the tourniquet to slide back and forth over the feeding tube and enable loosening or tightening, respectively, of the band. The heart is exposed through a standard midline sternotomy, 


\section{Abbreviations and Acronyms \\ $\mathrm{d}$-TGA $=\mathrm{d}$-transposition of the great arteries \\ $\mathrm{LV} \quad=$ left ventricular \\ $\mathrm{TAPAB}=$ transcutaneously adjustable pulmonary artery band}

generally opening only the upper portion of the pericardium to dissect the main pulmonary artery. An additional small incision is made on the anterior chest wall in either the right or left second intercostal space, and the back end of the device is passed through this window, which can be easily accessed for future band adjustments. Once it is passed through, the band is applied under Doppler/echocardiographic and direct pressure measurement guidance. After the optimal degree of banding is attained, titanium clips are applied to the back end of the feeding tube to secure the tourniquet. This clipped portion is tunneled subcutaneously, and the wound is closed for future access. A typical postoperative chest radiograph with the tunneled portion of the band in the second interspace is shown in Figure 2 .

\section{RESULTS}

From 1995 to 2011, 11 patients underwent placement of a TAPAB for the purpose of retraining the morphologic left ventricle for a subsequent arterial switch operation, and this subset was subjected to analysis. Ten patients had congenitally corrected transposition of the great arteries. In 3 of these patients, an associated ventricular septal defect had been previously closed, and 7 patients had been born with an intact ventricular septum. The remaining 13-year-old child had undergone a Senning procedure and ventricular septal defect closure for d-TGA/ventricular septal defect shortly after birth. In all cases, systemic morphologic right ventricular dysfunction and variable amounts of tricuspid valve regurgitation were present. Pulmonary artery band application for $\mathrm{LV}$ retraining is performed to achieve an ultimate goal of a left/right ventricular pressure ratio of 0.8 or more before an arterial switch operation is undertaken. However, this goal is often limited by acute LV dysfunction and newonset mitral valve regurgitation during band application. Band adjustment is, therefore, guided by these clinical parameters and the Doppler echocardiographic findings.

The mean age at TAPAB placement was 5.5 years (median, 4.2; range, 0.7-13.6). In 10 patients, the TAPAB was performed as the only procedure. One patient also underwent mitral valve repair for significant regurgitation. No complications resulted from band placement, and all patients were discharged home after a mean hospital stay of 6.6 days (median, 5.5; range, 4-11). The mean interval to extubation was 1.7 days (median, 1 ; range, 1-2) and the mean interval to intensive care unit discharge was 1.6 days (median, 1.5; range, 1-3).

One or more band adjustments were required in 6 of the 11 patients ( 1 loosened and 5 tightened, $55 \%$ ) at a mean of 281 days after initial band placement (median, 98 days; range, 0-917; Table 1). All were accomplished successfully by exposing the band in the subcutaneous tissue of the anterior chest wall and performing the adjustment under Doppler echocardiographic guidance. One patient developed ventricular dysfunction within 24 hours after the initial TAPAB placement and underwent successful loosening, eventually achieving adequate retraining and undergoing a double switch repair. One patient underwent band tightening 7 days after the initial placement when the gradient was found to have substantially decreased. However, this patient required complete band removal 4 months later because of progressive LV dysfunction and was not a candidate for a double switch procedure. Of the remaining 4 patients who required band tightening, 3 underwent 1 tightening procedure and all went on to undergo double switch conversion. One patient underwent TAPAB tightening 2 years later and underwent additional tightening 3 days after the second adjustment, subsequently undergoing a double switch procedure.

Of the 5 remaining patients not undergoing band adjustments, 1 had undergone initial TAPAB placement only 1 month previously, 1 was a patient with d-TGA who was lost to follow-up, 2 were successfully retrained without the need for additional adjustment and underwent the double switch procedure, and 1 patient remained banded with biventricular dysfunction and was recently evaluated with the anticipation of transplantation. When stratified by patient age at initial band placement, of the 8 patients who were younger than 10 years old, 7 became arterial switch candidates and 1 was awaiting anatomic repair. The mean age of this group was 3.1 years (range, 0.7-7). Of the 3 bands placed in those older than 10 years (age, 10, 12, and 13 years), none underwent conversion to a double switch repair. The 12-year-old patient underwent band removal, the 10-year-old patient remains banded with plans for transplantation, and the 13-year-old patient with d-TGA with a Senning repair was lost to follow-up.

\section{DISCUSSION}

Several large series, including our own, have demonstrated the feasibility of staged retraining of the morphologic left ventricle for conversion to an arterial switch procedure and have established guidelines for successful LV retraining before undertaking anatomic repair. ${ }^{1-4}$ Although attempts to perform staged LV retraining by the application of increased afterload to the ventricle using a pulmonary artery band were less successful in older candidates, younger patients can often be successfully retrained with gradual increments in afterload to achieve systemic LV pressure with normal ventricular function. There is both experimental and clinical evidence that a sustained afterload suddenly imposed by a nonadjustable band applied with too significant an afterload to the left ventricle is deleterious to $\mathrm{LV}$ function and $\mathrm{LV}$ retraining. ${ }^{5}$ 


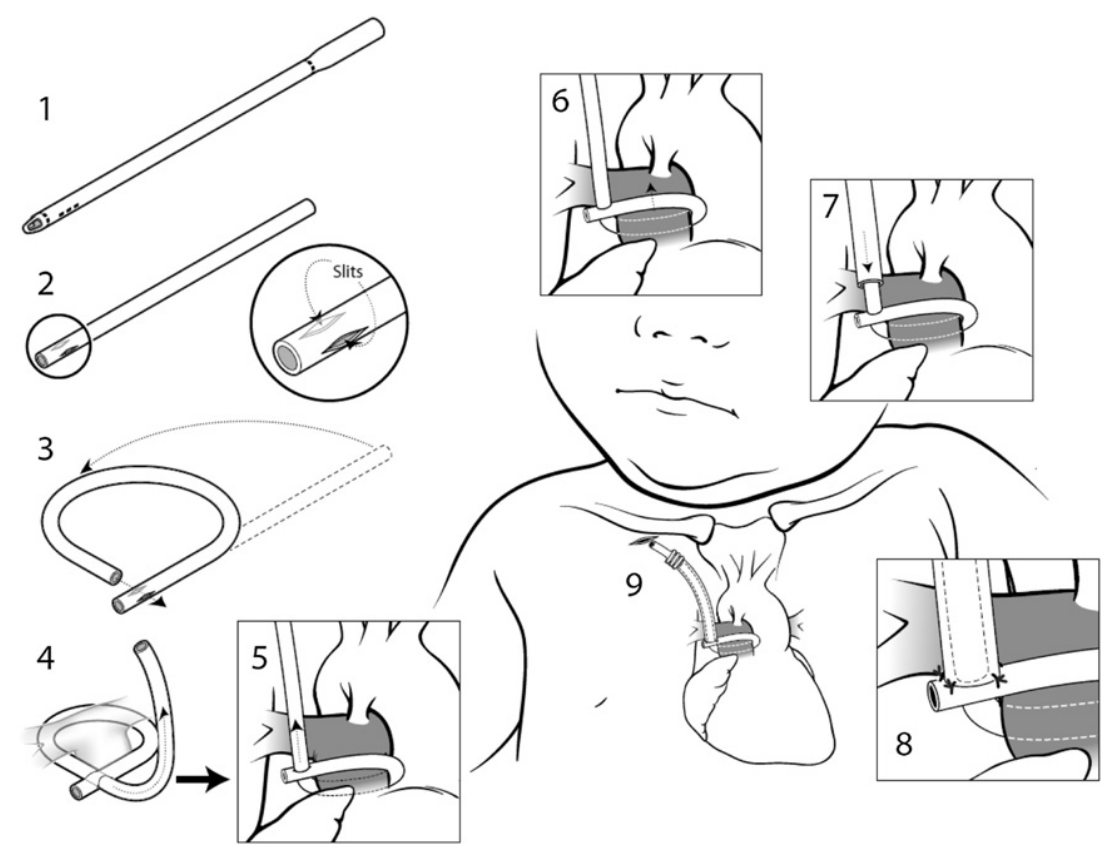

FIGURE 1. Construction of the transcutaneously adjustable pulmonary artery band (TAPAB). See text for details. By constructing a fenestration in the end of the feeding tube, it can be looped around itself to encircle the pulmonary artery $(1-5)$. Using the urinary catheter as a tourniquet $(6,7)$ and securing it to 1 end of the feeding tube (8) results in a band that can be tightened or loosened by manipulating the distal end, which is passed through the chest wall and clipped to maintain the desired degree of afterload stress (9).

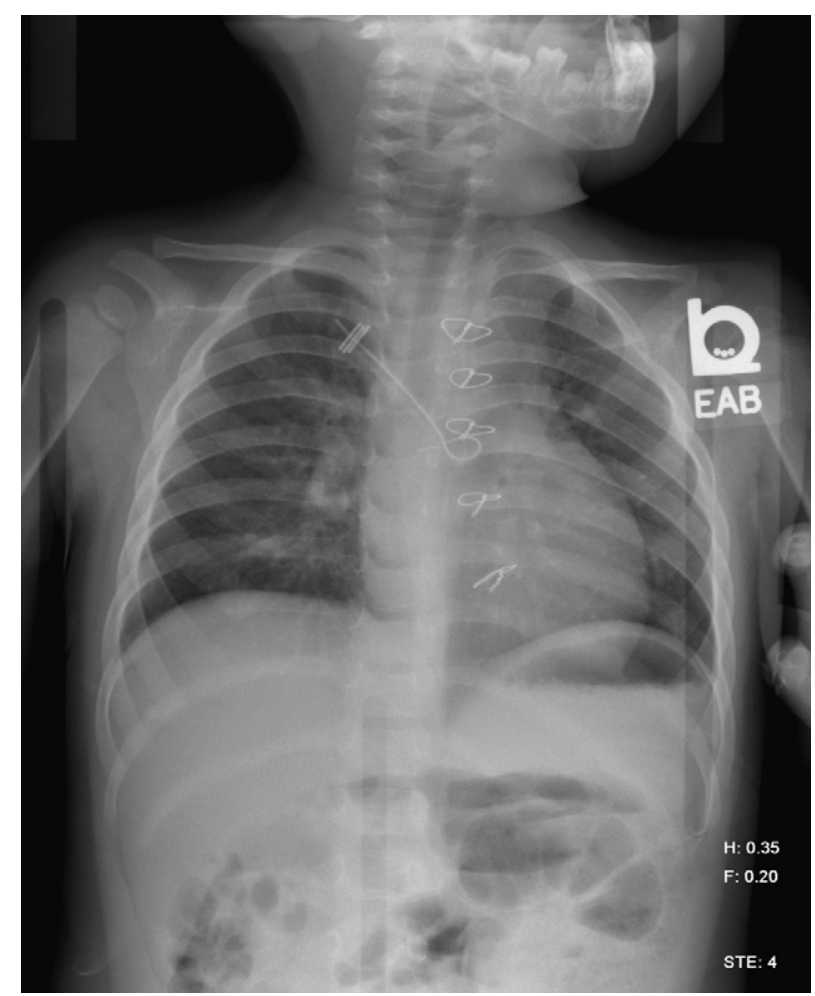

FIGURE 2. Postoperative chest radiograph demonstrating transcutaneously adjustable pulmonary artery band $(T A P A B)$. The looped portion of the feeding tube is visible on the pulmonary artery and the end with the clips is tunneled into the subcutaneous tissue of the second interspace.
This technique can result in subendocardial ischemia, myocardial fibrosis, and ventricular dysfunction that can be irreversible. Protocols in which a gradual and progressive increase in afterload stress is applied have resulted in less fibrosis in experimental settings and are likely to be more successful in achieving satisfactory increases in LV mass with normal ventricular function.

The clinical application of a gradual increase in afterload with conventional banding of the pulmonary artery would require repeated major operations before successful anatomic repair could be used. This concern has led to the development of multiple devices and alternate off-label banding techniques. The most notable current examples include the clinical experience with the FloWatch device, ${ }^{6-8}$ the use of an adjustable gastric band device, ${ }^{9}$ and several thorascopic and openly applied adjustable homemade devices. ${ }^{10-13}$ The FloWatch device is conceptually sound but is not available in the United States and is not applicable to all size patients and all anatomic subtypes.

Our technique of TAPAB, as described in the present report, is a reliable and safe method of applying a gradual increase in LV afterload that can be performed as a minor procedure. Importantly, the band is configured to allow both tightening and loosening, thereby ensuring safety if too high an afterload stress is applied and LV dysfunction results. Additionally, the knowledge that this technique is reliable and reproducible affords the operating surgeon the freedom to apply the band very gradually, erring on 
TABLE 1. Peak instantaneous pressure gradients at initial pulmonary artery band placement and subsequent interval adjustments

\begin{tabular}{|c|c|c|c|c|c|c|c|}
\hline Pt. no. & $\begin{array}{c}\text { Initial PA } \\
\text { band PIPG } \\
(\mathbf{m m ~ H g})\end{array}$ & Interval & $\begin{array}{c}\text { Second PA band } \\
\text { PIPG (mm Hg) } \\
\text { before, after }\end{array}$ & Interval & $\begin{array}{c}\text { Third PA band } \\
\text { PIPG (mm Hg) } \\
\text { before, after }\end{array}$ & $\begin{array}{c}\text { Interval to } \\
\text { double switch }\end{array}$ & $\begin{array}{c}\text { PIPG before } \\
\text { double switch }(\mathrm{mm} \mathrm{Hg})\end{array}$ \\
\hline 1 & 45 & $7 \mathrm{~d}$ & 30,50 & NA & NA & 3.8 & 50 \\
\hline 2 & 55 & $7 \mathrm{~d}$ & 30,50 & $3.6 \mathrm{mo}$ & Removed & NA & Removed \\
\hline 3 & 40 & NA & NA & NA & NA & NA & Transplantation evaluation \\
\hline 4 & 47 & NA & NA & NA & NA & NA & Lost to follow-up \\
\hline 5 & 40 & $2 \mathrm{~d}$ & 45,105 & NA & NA & $2 \mathrm{mo}$ & 80 \\
\hline 6 & 30 & NA & NA & NA & NA & $5 \mathrm{mo}$ & 33 \\
\hline 7 & 30 & $31 \mathrm{mo}$ & 35,60 & $4 \mathrm{~d}$ & 40,55 & $18 \mathrm{mo}$ & 75 \\
\hline 8 & 45 & $19 \mathrm{mo}$ & 40,50 & NA & NA & $10 \mathrm{mo}$ & 80 \\
\hline 9 & 60 & NA & NA & NA & NA & $9 \mathrm{mo}$ & 83 \\
\hline 10 & 40 & $0 \mathrm{~d}$ & 40,35 & NA & NA & $15 \mathrm{mo}$ & 83 \\
\hline 11 & 35 & NA & NA & NA & NA & NA & Awaiting double switch \\
\hline
\end{tabular}

Pt. no., Patient number; PIPG, peak instantaneous pressure gradient; $P A$, pulmonary artery; $N A$, not available.

the side of safety, with the realization that future adjustments can be performed at any point without the need to reenter the chest. We have not experienced any complications or technique failures with its use and believe it to be a preferable alternative to conventional banding for LV retraining.

\section{References}

1. Poirier NC, Mee RB. Left ventricular reconditioning and anatomical correction for systemic right ventricular dysfunction. Semin Thorac Cardiovasc Surg Pediatr Card Surg Ann. 2000;3:198-215.

2. Winlaw DS, McGuirk SP, Balmer C, Langley SM, Griselli M, Stümper O, et al. Intention-to-treat analysis of pulmonary artery banding in conditions with a morphological right ventricle in the systemic circulation with a view to anatomic biventricular repair. Circulation. 2005;111:405-11.

3. Padalino MA, Stellin G, Brawn WJ, Fasoli G, Daliento L, Milanesi O, et al. Arterial switch operation after left ventricular retraining in the adult. Ann Thorac Surg. 2000;70:1753-7.

4. Devaney EJ, Charpie JR, Ohye RG, Bove EL. Combined arterial switch and Senning operation for congenitally corrected transposition of the great arteries: patient selection and intermediate-term results. J Thorac Cardiovasc Surg. 2003; 125:500-7.

5. Le Bret E, Lupoglazoff JM, Borenstein N, Fromont G, Laborde F, Bachet J, et al Cardiac "fitness" training: an experimental comparative study of three methods of pulmonary artery banding for ventricular training. Ann Thorac Surg. 2005;79: 198-203.

6. Davis MC. Use of a new implantable adjustable pulmonary artery banding device: a report of two patients. J Extra Corpor Technol. 2008;40:65-7.

7. Corno AF, Ladusans EJ, Pozzi M, Kerr SJ. FloWatch versus conventional pulmonary artery banding. Thorac Cardiovasc Surg. 2007;134:1413-20.

8. Sekarski N, Fridez P, Corno AF, Von Segesser LK, Meijboom EJ. Dopplerguided regulation of a telemetrically operated adjustable pulmonary banding system. J Am Coll Cardiol. 2004;44:1087-94.

9. Boudjemline Y, Pineau E, Bonnet C, Mollet A, Abadir S, Bonnet D, et al. Offlabel use of an adjustable gastric banding system for pulmonary artery banding. Thorac Cardiovasc Surg. 2006;131:1130-5.

10. Leeuwenburgh BP, Schoof PH, Steendijk P, Baan J, Mooi WJ, Helbing WA. Chronic and adjustable pulmonary artery banding. I Thorac Cardiovasc Surg. 2003;125:231-7.

11. Le Bret E, Bonhoeffer P, Folliguet TA, Sidi D, Laborde F, de Leval MR, et al. A new percutaneously adjustable, thoracoscopically implantable, pulmonary artery banding: an experimental study. Ann Thorac Surg. 2001; 72:1358-61.

12. Schlensak C, Sarai K, Gildein HP, Beyersdorf F. Pulmonary artery banding with a novel percutaneously, bidirectionally adjustable device. Eur J Cardiothorac Surg. 1997;12:931-3.

13. Choudhary SK, Talwar S, Airan B, Mohapatra R, Juneja R, Kothari SS, et al. A new technique of percutaneously adjustable pulmonary artery banding. $J$ Thorac Cardiovasc Surg. 2006;131:621-4. 